\title{
molecules
}

ISSN 1420-3049

www.mdpi.com/journal/molecules

Article

\section{miRNA Stability in Frozen Plasma Samples}

Francesca Balzano ${ }^{1}$, Marta Deiana ${ }^{2}$, Silvia Dei Giudici ${ }^{3}$, Annalisa Oggiano ${ }^{3}$, Angela Baralla ${ }^{1}$, Sara Pasella ${ }^{1}$, Andrea Mannu ${ }^{1}$, Mario Pescatori ${ }^{1}$, Baingio Porcu ${ }^{1}$, Giuseppe Fanciulli ${ }^{4}$, Angelo Zinellu ${ }^{1}$, Ciriaco Carru ${ }^{1}$ and Luca Deiana ${ }^{1,2, *}$

1 Department of Biomedical Sciences, University of Sassari, vl. San Pietro 43b, Sassari 07100, Italy; E-Mails: mariafrancesca22@virgilio.it (F.B.); angela.b3@virgilio.it (A.B.); sarapasella18@gmail.com (S.P.); amannu@tiscali.it (A.M.); mariopescatori@gmail.com (M.P.); baingio@gmail.com (B.P.); azinellu@uniss.it (A.Z.); carru@uniss.it (C.C.)

2 Associazione “L’Isola dei Centenari”, Via Milano 4, Sassari 07100, Italy;

E-Mail: isoladeicentenari@gmail.com

3 Istituto Zooprofilattico Sperimentale della Sardegna, Via Vienna 2, Sassari 07100, Italy; E-Mails: silvia.deigiudici@izs-sardegna.it (S.D.G.); annalisa.oggiano@izs-sardegna.it (A.O.)

4 Department of Clinical and Experimental Medicine, University of Sassari, vl. San Pietro 8, Sassari 07100, Italy; E-Mail: gfanciu@uniss.it

* Author to whom correspondence should be addressed; E-Mail: proflucadeiana@gmail.com; Tel./Fax: +39-07-9228275.

Academic Editor: Derek J. McPhee

Received: 24 July 2015 / Accepted: 13 October 2015 / Published: 20 October 2015

Abstract: MicroRNAs (miRNAs) represent a family of small non-coding ribonucleic acids that post-transcriptionally inhibits the expression of their target messenger RNAs (mRNAs), thereby acting as general gene repressors. In this study we examined the relative quantity and stability of miRNA subjected to a long period of freezing; we compared the stability of eight miRNAs in the plasma of five human healthy controls before freezing and after six and 12 months of storage at $-80^{\circ} \mathrm{C}$. In addition, we examined the plasma frozen for 14 years and the amount of miRNA still available. Using a Life Technologies protocol to amplify and quantify plasma miRNAs from EDTA (Ethylene Diamine Tetraacetic Acid)-treated blood, we analyzed the stability of eight miRNAs, (miR-125b-5p, miR-425-5p, miR-200b-5p, miR-200c-3p, miR-579-3p, miR-212-3p, miR-126-3p, and miR-21-5p). The miRNAs analyzed showed a high stability and long frozen half-life. 
Keywords: miRNA; stability; long freezing times; sequences AU or UA

\section{Introduction}

MicroRNAs (miRNAs) are 20-22-nucleotide-long, non-coding RNA molecules that post-transcriptionally regulate gene expression by base-pairing with the $3^{\prime}$ untranslated region of complementary messenger RNA targets [1,2]. The miRNA is associated with the RNA-induced silencing complex (RISC) [3] and this complex binds target mRNAs through the complementary perfect region seed and partially complementary sequences tail and reduces their translation and/or stability [4]. They regulate diverse biological processes, and bioinformatics data indicate that each miRNA can control hundreds of gene targets, underscoring the potential influence of miRNAs on almost every genetic pathway [5-10]. Growing evidence indicates that miRNAs exist not only in cells, but also in a variety of body fluids including blood [11]. Extracellular miRNAs are easy to detect in body fluids, and they have been considered as potential biomarkers for specific diseases [12]. The first studies revealed that these circulating miRNAs may be delivered to recipient cells where they can regulate translation of target genes [13,14]. While many studies have focused on the study of miRNA expression in physiological and pathological processes, various technical problems related to miRNA isolation have simultaneously emerged and the stability of the storage of miRNA in biological samples has been questioned $[13,14]$. The miRNAs in plasma can be quantitatively detected by methods such as real-time PCR and microarrays [14]. Here we investigate the stability of miRNAs isolated from clinically healthy donors, and evaluate the abundance and solidity of miRNAs subjected to a long period of freezing. To assess the stability of the miRNAs, a real-time PCR analysis was performed on a panel of eight miRNAs from freshly isolated plasma samples and from samples subjected to six and 12 months of storage at $-80{ }^{\circ} \mathrm{C}$. Surprisingly, the expression of the tested miRNAs was stable for six and 12 months at $-80{ }^{\circ} \mathrm{C}$. miRNAs isolated from stored samples did not show any significant degradation. Moreover, the real-time PCR analysis was repeatedly performed on plasma samples stored over a period of $\sim 14$ years. The results showed that the samples were stable for four years and then began to decrease, remaining detectable. All samples were recruited from the biobank of the longevity AKeA Project (project approved by the local Ethics committee) $[15,16]$.

\section{Results and Discussion}

The raw values, the mean and standard deviation of $\mathrm{Ct}$ (threshold cycle) of miRNAs and U6snRNA analyzed are reported in supplementary Tables S1 and S2. Data for all targets resulted not normally distributed. The Kruskal-Wallis test showed no significant differences between years only for U6snRNA ( $p=0.977)$, miR200b-5p $(p=0.099)$, miR-212-3p $(p=0.082)$, and miR579-3p $(p=0.079)$. The statistical analysis supported our decision to use the U6snRNA as normalizer for the real-time PCR analysis because of its greater stability between groups of samples. We analyzed eight miRNAs: miR-125b-5p; miR-425-5p; miR-200b-5p; miR-200c-3p; miR-579-3p; miR-212-3p; miR-126-3p; and miR-21-5p identified with a number from 1 to 8 in all graphics and tables. We performed a comparison between the level of miRNA in fresh plasma samples and the level of miRNA in frozen samples for different storage periods. In particular, the fresh samples were analyzed at the time of collection, and after six and 
12 months of storage at $-80{ }^{\circ} \mathrm{C}$. miRNA levels in plasma samples collected in 1999, 2002, 2003, 2009, and 2010 and stored at $-80{ }^{\circ} \mathrm{C}$ were also evaluated and compared to fresh samples. The $\mathrm{Ct}$ value of some samples frozen for six or 12 months showed to be less than that of paired fresh samples; this could be explained with technical error in the RNA extraction and/or RT-PCR procedure. Figure 1 and Table 1 show the relative concentration of the miRNAs analyzed in this study in the samples frozen for 12 months at $-80{ }^{\circ} \mathrm{C}$ compared with fresh samples. As in the samples frozen for six months, these results show that there are no significant differences in the miRNA levels between fresh and frozen samples. The same results were obtained in the comparison between fresh samples and samples collected in 2010 and stored at $-80{ }^{\circ} \mathrm{C}$ (Figure 2 and Table 2). The comparative analysis with the samples collected in 2002, 2003, and 2009 (Figure 3 and Table 3) showed that miRNA 126-3p (\#7) had a concentration significantly lower $(p=0.008)$ than fresh samples, while the other miRNAs showed no significant differences. Finally, in the samples collected in 1999, all miRNAs had a significantly low concentration, except for the miRNA 212-5p (\#6) (Figure 4 and Table 4). These results show that the miRNAs decay at different times. During the first four years we did not observe significant differences in the concentration of miRNAs in fresh samples when compared to frozen samples. All miRNAs begin to decline after five years of freezing, while miR-212-3p does not decay and remains stable after 14 years of freezing. All miRNAs studied seem to show differences in stability in relation to the number of the AU or UA motifs in their sequences. We looked for a possible explanation for this result. In 2009, Sethi and Lukiw suggested a decline linked to the number of AU sequences in the miRNAs under investigation in their study [17]. We observed this result in our samples subjected to freezing in the various time intervals. miRNA 212-3p has one AU sequence, all other miRNAs analyzed have from two to five AU sequences. miRNA 126-3p, which has five AU sequences, was the first to decrease its concentration after five years. We think that miRNA stability is related to the absence of AU sequences in seed and tail miRNA regions.

Table 1. Relative expression (concentration), standard error, 95\% confidence interval (C.I.), and $p$-value of miRNAs analyzed in this study (samples frozen for 12 months compared with fresh samples). $p$-value $(\geq 0.05)$ shows that there are no significant differences.

\begin{tabular}{cllcccc}
\hline miRNA & Type & Reaction Efficiency & Expression & Std. Error & 95\% C.I. & P(H1) \\
\hline 1 & TRG & 1 & 2.210 & $0.181-16.260$ & $0.080-246.143$ & 0.468 \\
2 & TRG & 1 & 2.141 & $0.388-76.793$ & $0.039-683.002$ & 0.592 \\
3 & TRG & 1 & 0.271 & $0.016-1.566$ & $0.007-38.257$ & 0.331 \\
4 & TRG & 1 & 2.039 & $0.563-22.424$ & $0.051-170.211$ & 0.497 \\
5 & TRG & 1 & 6.907 & $0.377-496.960$ & $0.020-27.857$ & 0.365 \\
6 & TRG & 1 & 1.247 & $0.024-128.740$ & $0.011-4.842$ & 0.951 \\
7 & TRG & 1 & 1.211 & $0.380-6.831$ & $0.043-34.196$ & 0.765 \\
8 & TRG & 1 & 0.342 & $0.061-3.016$ & $0.001-73.104$ & 0.502 \\
U6snRNA & REF & 1 & 1 & & & \\
\hline
\end{tabular}




\section{Relative expression}

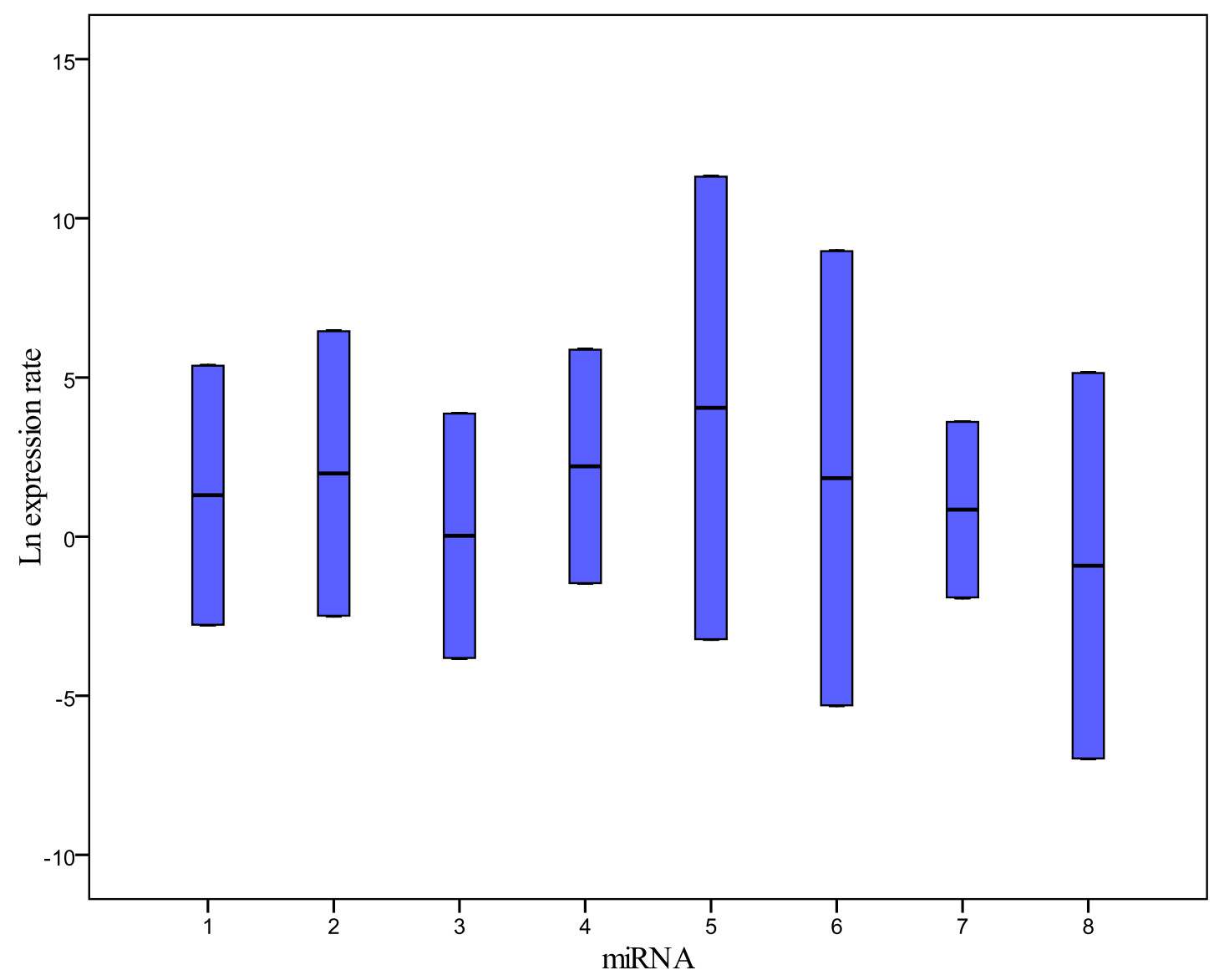

Figure 1. Relative expression (concentration) of the miRNAs analyzed in this study in samples frozen for 12 months compared with fresh samples. $1=$ miR-125b-5p; $2=$ miR-425-5p; $3=\operatorname{miR}-200 \mathrm{~b}-5 \mathrm{p} ; 4=\operatorname{miR}-200 \mathrm{c}-3 \mathrm{p} ; 5=\operatorname{miR}-579-3 \mathrm{p} ; 6=\operatorname{miR}-212-3 \mathrm{p} ; 7=\operatorname{miR}-126-3 \mathrm{p}$; $8=\operatorname{miR}-21-5 \mathrm{p}$.

Table 2. Relative expression (concentration), standard error, $95 \%$ confidence interval (C.I.), and $p$-value of miRNAs analyzed in this study (samples collected in 2010 and stored at $-80{ }^{\circ} \mathrm{C}$ compared with fresh samples). $p$-value $(\geq 0.05)$ shows that there are no significant differences.

\begin{tabular}{ccccccc}
\hline miRNA & Type & Reaction Efficiency & Expression & Std. Error & 95\% C.I. & P(H1) \\
\hline 1 & TRG & 1 & 6.088 & $0.376-118.479$ & $0.169-5.649$ & 0.300 \\
2 & TRG & 1 & 3.430 & $0.237-96.389$ & $0.132-11.035$ & 0.543 \\
3 & TRG & 1 & 0.205 & $0.001-58.136$ & $0.001-1.239$ & 0.496 \\
4 & TRG & 1 & 1.273 & $0.060-76.914$ & $0.031-4.285$ & 0.915 \\
5 & TRG & 1 & 2.900 & $0.205-55.911$ & $0.125-3.116$ & 0.526 \\
6 & TRG & 1 & 7.825 & $0.441-1.673 .136$ & $0.115-14.474$ & 0.315 \\
7 & TRG & 1 & 0.373 & $0.089-2.646$ & $0.050-11.195$ & 0.254 \\
8 & TRG & 1 & 3.317 & $0.210-148.920$ & $0.144-5.319$ & 0.536 \\
U6snRNA & REF & 1 & 1.000 & & & \\
\hline
\end{tabular}




\section{Relative expression}

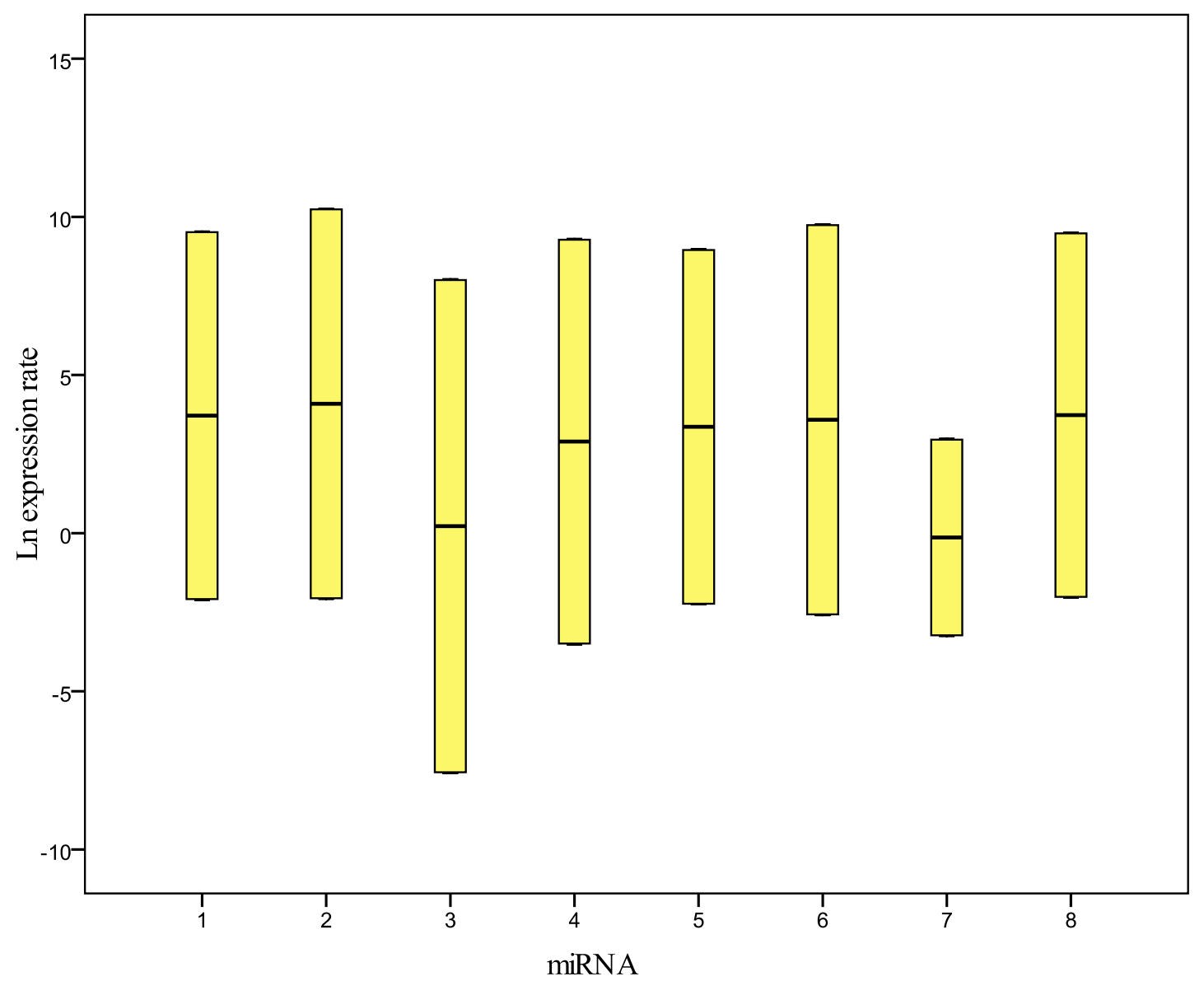

Figure 2. Relative expression (concentration) of the miRNAs analyzed in this study in samples collected in 2010 and frozen at $-80{ }^{\circ} \mathrm{C}$ compared with fresh samples. $1=$ miR-125b-5p; $2=\operatorname{miR}-425-5 \mathrm{p} ; 3=\operatorname{miR}-200 \mathrm{~b}-5 \mathrm{p} ; 4=\operatorname{miR}-200 \mathrm{c}-3 \mathrm{p} ; 5=\operatorname{miR}-579-3 \mathrm{p} ; 6=\operatorname{miR}-212-3 \mathrm{p}$; $7=\operatorname{miR}-126-3 p ; 8=\operatorname{miR}-21-5 p$.

Table 3. Relative expression (concentration), standard error, $95 \%$ confidence interval (C.I.), and $p$-value of miRNAs analyzed in this study (samples collected in 2009 and stored at $-80{ }^{\circ} \mathrm{C}$ compared with fresh samples). miRNA 126b-5p (\#7) decreased significantly ( $p=0.021)$ while all other miRNAs show no significant differences.

\begin{tabular}{cccccccc}
\hline miRNA & Type & Reaction Efficiency & Expression & Std. Error & 95\% C.I. & P(H1) & Result \\
\hline 1 & TRG & 1 & 1.446 & $0.075-22.084$ & $0.005-399.228$ & 0.762 & \\
2 & TRG & 1 & 0.355 & $0.027-5.061$ & $0.003-131.362$ & 0.418 & \\
3 & TRG & 1 & 0.110 & $0.002-2.424$ & $0.002-79.778$ & 0.120 & \\
4 & TRG & 1 & 0.099 & $0.005-2.367$ & $0.000-36.781$ & 0.065 & \\
5 & TRG & 1 & 0.308 & $0.014-7.950$ & $0.000-156.536$ & 0.468 & \\
6 & TRG & 1 & 9.120 & $0.817-168.704$ & $0.030-18.989$ & 0.159 & \\
7 & TRG & 1 & 0.093 & $0.020-0.479$ & $0.001-5.080$ & 0.008 & DOWN \\
8 & TRG & 1 & 1.229 & $0.104-16.032$ & $0.012-505.934$ & 0.858 & \\
U6snRNA & REF & 1 & 1.000 & & & & \\
\hline
\end{tabular}




\section{Relative Expression}

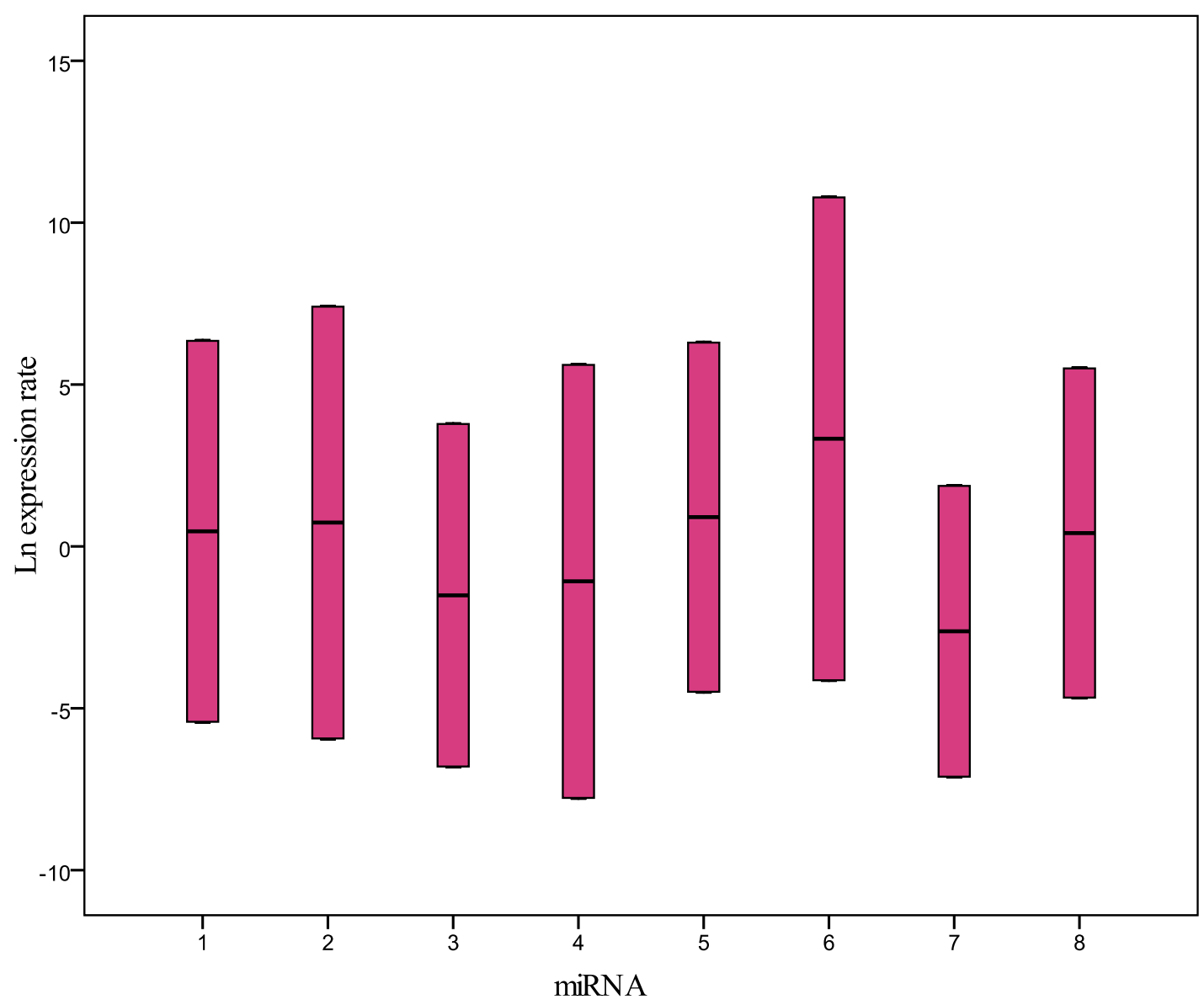

Figure 3. Relative expression (concentration) of the miRNAs analyzed in this study in samples collected in 2009 and frozen at $-80{ }^{\circ} \mathrm{C}$ compared with fresh samples. $1=$ miR-125b-5p; $2=\operatorname{miR}-425-5 \mathrm{p} ; 3=\operatorname{miR}-200 \mathrm{~b}-5 \mathrm{p} ; 4=\operatorname{miR}-200 \mathrm{c}-3 \mathrm{p} ; 5=\operatorname{miR}-579-3 \mathrm{p} ; 6=\operatorname{miR}-212-3 \mathrm{p}$; $7=\operatorname{miR}-126-3 \mathrm{p} ; 8=\mathrm{miR}-21-5 \mathrm{p}$.

Table 4. Relative expression (concentration), standard error, $95 \%$ confidence interval (C.I.), and $p$-value of miRNAs analyzed in this study (samples collected in 1999 and stored at $-80{ }^{\circ} \mathrm{C}$ compared with fresh samples). All miRNAs decreased significantly, except miRNA-212-3p (\#6) that shows no significant differences.

\begin{tabular}{cccccccc}
\hline miRNA & Type & Reaction Efficiency & Expression & Std. Error & $\mathbf{9 5 \%}$ C.I. & P(H1) & Result \\
\hline 1 & TRG & 1 & 0.009 & $0.000-0.326$ & $0.000-15.647$ & 0.007 & DOWN \\
2 & TRG & 1 & 0.010 & $0.000-0.739$ & $0.000-56.166$ & 0.017 & DOWN \\
3 & TRG & 1 & 0.024 & $0.003-0.372$ & $0.000-10.244$ & 0.008 & DOWN \\
4 & TRG & 1 & 0.001 & $0.000-0.009$ & $0.000-0.145$ & 0.000 & DOWN \\
5 & TRG & 1 & 0.008 & $0.000-0.838$ & $0.000-39.763$ & 0.021 & DOWN \\
6 & TRG & 1 & 2.095 & $0.041-90.056$ & $0.011-2.538$ & 0.652 & \\
7 & TRG & 1 & 0.059 & $0.005-0.882$ & $0.002-10.576$ & 0.007 & DOWN \\
8 & TRG & 1 & 0.002 & $0.000-0.095$ & $0.000-11.618$ & 0.002 & DOWN \\
U6snRNA & REF & 1 & 1.000 & & & & \\
\hline
\end{tabular}




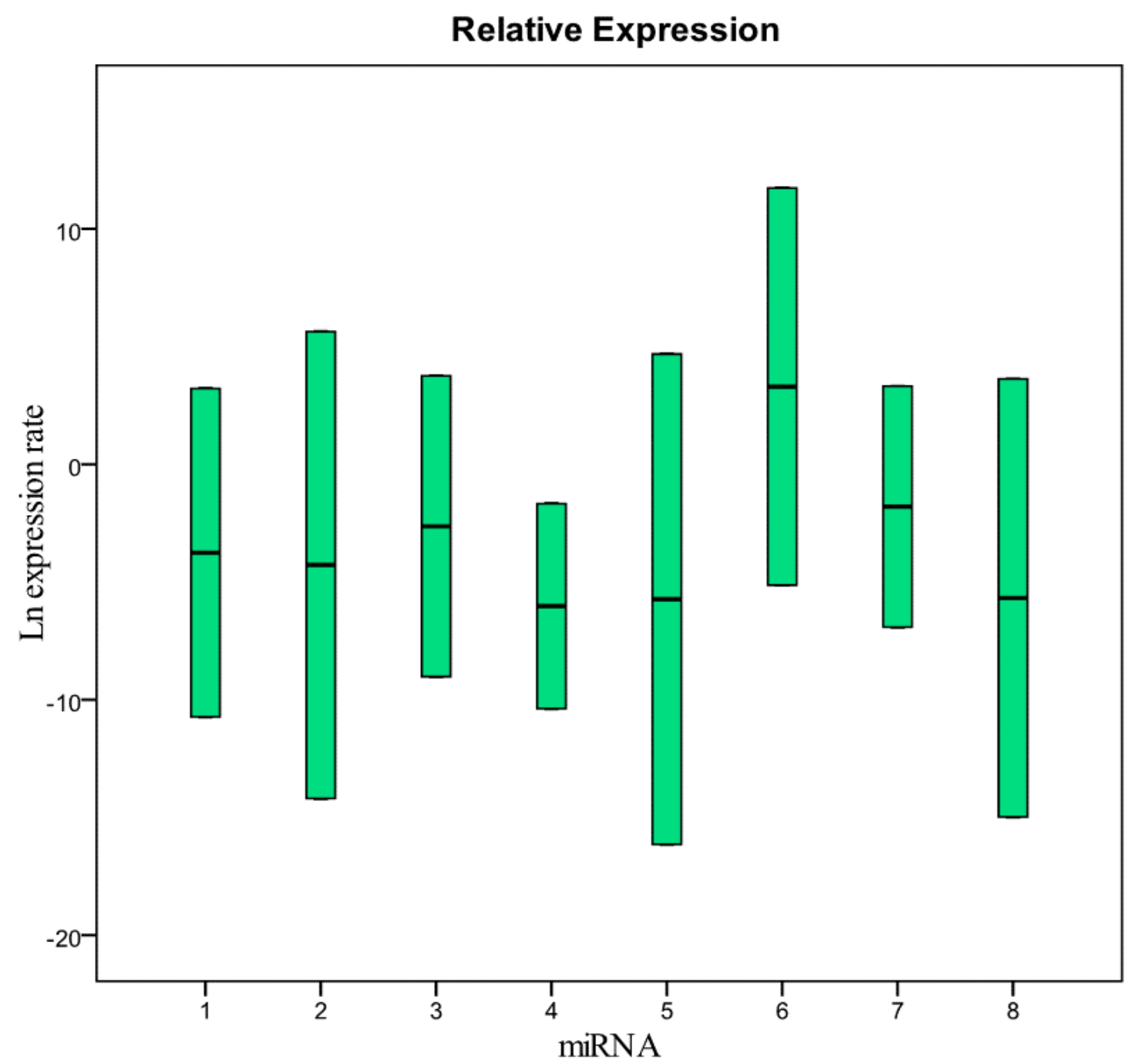

Figure 4. Relative expression (concentration) of the miRNAs analyzed in this study in samples collected in 1999 and frozen at $-80{ }^{\circ} \mathrm{C}$ compared with fresh samples. $1=$ miR-125b-5p; $2=\operatorname{miR}-425-5 \mathrm{p} ; 3=\operatorname{miR}-200 \mathrm{~b}-5 \mathrm{p} ; 4=\operatorname{miR}-200 \mathrm{c}-3 \mathrm{p} ; 5=\operatorname{miR}-579-3 \mathrm{p} ; 6=\operatorname{miR}-212-3 \mathrm{p}$; $7=\operatorname{miR}-126-3 p ; 8=\operatorname{miR}-21-5 p$.

\section{Experimental Section}

\subsection{Human Plasma Samples}

Plasma samples were from subjects aged between 30 and 50 years. The donors were healthy volunteers recruited from the longevity AKeA Project (project approved by the local bioethics committee). Subjects signed a written consent prior to blood sampling. Blood samples were collected early in the morning (to reduce the biological variability) by venipucture into a vacutainer (Greiner Bio-One, Monroe, NC, USA) containing K2 EDTA as an anticoagulant. Then we proceeded to the separation of the plasma by centrifugation at $2500 \mathrm{~g}$ for $15 \mathrm{~min}$ at $4{ }^{\circ} \mathrm{C}$. The supernatant containing the plasma was divided into a defined number of aliquots of $200 \mu \mathrm{L}$ each. Five samples were collected in 2013 and analyzed directly or after a storage of six and 12 months at $-80^{\circ} \mathrm{C}$. The other 24 samples from different donors were from the AkeA Project Biobank, collected in 1999, 2002, 2003, 2009, and 2010, and had been stored at 
$-80{ }^{\circ} \mathrm{C}$. All defrozen samples were carefully mixed before analysis. The samples' characteristics are shown in Table 5.

Table 5. Sample Collection: number, collection year, and status of samples analyzed.

\begin{tabular}{ccc}
\hline Plasma Samples Number & Sample Status & Collection Year \\
\hline 5 & Fresh & 2013 \\
5 & Stored 6 months at $-80{ }^{\circ} \mathrm{C}$ & 2013 \\
5 & Stored 12 months at $-80{ }^{\circ} \mathrm{C}$ & 2013 \\
5 & Stored at $-80^{\circ} \mathrm{C}$ & 2010 \\
5 & Stored at $-80^{\circ} \mathrm{C}$ & 2009 \\
5 & Stored at $-80^{\circ} \mathrm{C}$ & 2003 \\
4 & Stored at $-80^{\circ} \mathrm{C}$ & 2002 \\
5 & Stored at $-80^{\circ} \mathrm{C}$ & 1999 \\
\hline
\end{tabular}

\subsection{RNA Extraction}

RNA was extracted from plasma fractions using miRNeasy Serum/Plasma Kit (50) (Qiagen, Milan, Italy) according to the manufacturer's instructions, with the final elution volume of $15 \mu \mathrm{L}$. Eight individual miRNAs (miR-125b-5p, miR-425-5p, miR-200b-5p, miR-200c-3p, miR-579-3p, miR-212-3p, miR-126-3p, and miR-21-5p) were selected based on their expression in the plasma of healthy donors and amplification efficiency and studies previously conducted $[18,19]$.

\section{3. qPCR Analysis}

The concentration level of mature miRNAs was tested by quantitative real-time PCR (qPCR) using TaqMan ${ }^{\circledR}$ MicroRNA Reverse Transcription Kit, Life Technologies (Carlsbad, CA, USA), for the reverse transcription. TaqMan ${ }^{\circledR}$ Universal Master Mix II, Life Technologies, was used for the PCR according to the manufacturer's instructions; 45 amplification cycles were performed. miRNA concentration levels were quantified using the IQ5, BIORAD, instrument (Milan, Italy). The U6snRNA was used for the data normalization [20,21]. Real-time PCR was done in duplicate. The miRNAs analyzed in this study were identified with progressive numbers from 1 to 8 (Table 6). The sequences and the identification symbols were retrieved from miRbase and are reported in Table 6 [22].

Table 6. miRNA collection: accession number, symbol, sequence, and identification number used in this study of miRNA analyzed.

\begin{tabular}{ccl}
\hline Accession & Symbol & \multicolumn{1}{c}{ Sequence ID Number } \\
\hline IMAT0000423 & hsa-miR-125b-5p & UCCCUGAGACCCUAACUUGUGA 1 \\
MIMAT0003393 & hsa-miR-425-5p & AAUGACACGAUCACUCCCGUUGA 2 \\
MIMAT0004571 & hsa-miR-200b-5p & CAUCUUACUGGGCAGCAUUGGA 3 \\
MIMAT0000617 & hsa-miR-200c-3p & UAAUACUGCCGGGUAAUGAUGGA 4 \\
MIMAT0003244 & hsa-miR-579-3p & UUCAUUUGGUAUAAACCGCGAUU 5 \\
MIMAT0000269 & hsa-miR-212-3p & UAACAGUCUCCAGUCACGGCC 6 \\
MIMAT0000445 & hsa-miR-126-3p & UCGUACCGUGAGUAAUAAUGCG 7 \\
MIMAT0000076 & hsa-miR-21-5p & UAGCUUAUCAGACUGAUGUUGA 8 \\
\hline
\end{tabular}




\subsection{Statistical Analysis and Real-Time PCR Data Analysis}

The raw $\mathrm{Ct}$ values for each miRNA and U6snRNA were checked for normal distribution. The Kruskal-Wallis test was applied to compare the groups (years) in each target. All the analysis and graphics were performed with the SPSS software version 17.0. Reverse transcription followed by polymerase chain reaction (RT-PCR) is the most suitable method for the detection and quantification of miRNA. It provides high sensitivity, good reproducibility, and a wide range quantification. Several mathematical algorithms have been developed to calculate a ratio of expression based on real-time PCR efficiency and the crossing point deviation of an unknown sample against a control. Then a software tool named REST ${ }^{\odot}$ (relative expression software) [23] was used, which compares two groups, with a maximum of 16 data points in a sample and 16 in a control group, for reference and up to four target genes. The mathematical model used is based on the PCR efficiencies and the crossing point average gap between sample and control. Subsequently, the reported expression or concentration of transcripts investigated are tested for significance by a randomization test. The relative concentration of the mature miRNAs was analyzed using the software REST. The non-parametric bootstrapping test was used to evaluate concentration differences of miRNAs between frozen and fresh samples. The five samples collected in 2013 were subjected to paired analysis between time-points (freshly isolated $v s$. stored six or 12 months at $-80{ }^{\circ} \mathrm{C}$ ) while all other samples were compared to fresh samples.

\section{Conclusions}

All miRNAs studied did not show differences in relative abundance between fresh samples and those subjected to four years of long freezing. The comparison between fresh and paired stored samples and the observed technical error highlights the need to optimize the current methods of analysis to improve their consistency. However, miRNA-212-3p showed to be significantly resistant to a long freezing time (14 years). The concentration of the other miRNAs has been proven to decrease after long freezing times, but they were still present, showing an elevated stability. As previously reported, all miRNAs studied seem to show differences in the stability in relation to the number of the sequences containing AU or UA [17]. We suppose that miRNAs' half-life and their degradation plays an important biological role and that the decline of miRNA is written in its sequence and is modulated by an editing substitution of a cytosine with an uracil during biogenesis. This may explain why in plants there is a perfect pairing of miRNA with the mRNA. In animals, pairing is perfect only in the seed region but not in the extra seed region and this fact can have a relevant role in the modulation of miRNAs' half-life. In animals, partial pairing between miRNA and the mRNA target site usually results in reduced protein expression through a variety of mechanisms. miRNA function seems to be distinct and less regulated in plants, in which miRNAs perfectly base-pair with targets and induce their degradation [24]. In conclusion, we think that this is a further control mechanism of the biological role played by miRNA. In animals, there is a more refined control of the "half-life" of miRNAs. These considerations could open new development into the utilization of miRNAs as therapeutic drugs.

\section{Supplementary Materials}

Supplementary materials can be accessed at: http://www.mdpi.com/1420-3049/20/10/19030/s1. 


\section{Acknowledgments}

We gratefully acknowledge the AKeA project equipe (Luca Deiana) and the Associazione "Isola dei Centenari”. Funding: L.D. was funded by Regione Autonoma della Sardegna, grant number L.R.7/2007. Funding provided to the institution Associazione "Isola dei Centenari" by Fondazione Banco di Sardegna, grant numbers Prot. 998/2007.0729, Prot. 906/2012-1046. The funders had no role in study design, data collection and analysis, decision to publish, or preparation of the manuscript.

\section{Author Contributions}

Conceived and designed the experiments: Luca Deiana, Francesca Balzano. Performed the experiments: Luca Deiana, Francesca Balzano, Marta Deiana, Ciriaco Carru. Analyzed data: Luca Deiana, Francesca Balzano, Silvia Dei Giudici, Annalisa Oggiano, Angela Baralla, Sara Pasella. Contributed reagents/materials/analysis tools: Luca Deiana, Marta Deiana. Wrote the paper: Francesca Balzano, Luca Deiana, Silvia Dei Giudici, Annalisa Oggiano, Angela Baralla, Sara Pasella. Technical support: Ciriaco Carru, Angelo Zinellu, Mario Pescatori, Andrea Mannu, Giuseppe Fanciulli, Baingio Porcu.

\section{Conflicts of Interest}

The authors declare no conflict of interest.

\section{References}

1. Bartel, D.P. MicroRNAs: Genomics, biogenesis, mechanism, and function. Cell 2004, 116, 281-297.

2. Mattick, J.S.; Makunin, I.V. Non-coding RNA. Hum. Mol. Genet. 2006, 1, 17-29.

3. Lund, E.; Guttinger, S.; Calado, A.; Dahlberg, J.E.; Kutay, U. Nuclear export of microRNA precursors. Science 2004, 303, 95-98.

4. Filipowicz, W.; Bhattacharyya, S.N.; Sonenberg, N. Mechanisms of post-transcriptional regulation by microRNAs: Are the answers in sight? Nat. Rev. Genet. 2008, 9, 102-114.

5. Lim, L.P.; Glasner, M.E.; Yekta, S.; Burge, C.B.; Bartel, D.P. Vertebrate microRNA genes. Science 2003, 299, 1540, doi:10.1126/science.1080372.

6. Ambros, V. The functions of animal microRNAs. Nature 2004, 431, 350-355.

7. Friedman, R.C.; Farh, K.K.; Burge, C.B.; Bartel, D.P. Most mammalian mRNAs are conserved targets of microRNAs. Genome Res. 2009, 19, 92-105.

8. Bartel, D.P.; Chen, C.Z. Micromanagers of gene expression: the potentially widespread influence of metazoan microRNAs. Nat. Rev. Genet. 2004, 5, 396-400.

9. Valencia-Sanchez, M.A.; Liu, J.; Hannon, G.J.; Parker, R. Control of translation and mRNA degradation by miRNAs and siRNAs. Genes Dev. 2006, 20, 515-524.

10. Plasterk, R.H. MicroRNAs in animal development. Cell 2006, 124, 877-881.

11. Weber, D.G.; Casjens, S.; Rozynek, P.; Lehnert, M.; Zilch-Schoneweis, S.; Bryk, O.; Taeger, D.; Gomolka, M.; Kreuzer, M.; Otten, H.; et al. Assessment of mRNA and microRNA stabilization in peripheral human blood for multicenter studies and biobanks. Biomark. Insights 2010, 5, 95-102.

12. Aijt, S.K. Circulating microRNA as biomarkers, therapeutic targets, and signaling. Mol. Sens. 2012, 12, 3359-3369. 
13. Ge, Q.; Zhou, Y.; Lu, J.; Bai, Y.; Xie, X.; Lu, Z. miRNA in Plasma Exosome is Stable under Different Storage Conditions. Molecules 2014, 19, 1568-1575.

14. Creemers, E.E.; Tijsen, A.J.; Pinto, Y.M. Circulating MicroRNAs Novel Biomarkers and Extracellular Communicators in Cardiovascular Disease? Circ. Res. 2012, 110, 483-495.

15. Deiana, L.; Ferrucci, L.; Pes, G.M.; Carru, C.; Delitala, G.; Ganau, A.; Mariotti, S.; Nieddu, A.; Pettinato, S.; Putzu, P.; et al. AKEntAnnos. The Sardinia Study of Extreme Longevity. Aging 1999, 11, 142-149.

16. Deiana, L.; Pes, G.M.; Carru, C.; Ferrucci, L.; Franceschi, C.; Baggio, G. The "Oldest Man on the Planet". J. Am. Geriatr. Soc. 2002, 50, 2098-2099.

17. Sethi, P.; Lukiw, W.J. Micro-RNA abundance and stability in human brain: Specific alterations in Alzheimer's disease temporal lobe neocortex. Neurosci. Lett. 2009, 459, 100-104.

18. Scholer, N.; Langer, C.; Dohner, H.; Buske, C.; Kuchenbauer, F. Serum microRNAs as a novel class of biomarkers: A comprehensive review of the literature. Exp. Hematol. 2010, 38, 1126-1130.

19. Scholer, N.; Langer, C.; Kuchenbauer, F. Circulating microRNAs as biomarkers-True Blood? Genome Med. 2011, 3, 72-74.

20. Benz, F.; Roderburg, C.; Vargas Cardenas, D.; Vucur, M.; Gautheron, J.; Koch, A.; Zimmermann, H.; Janssen, J.; Nieuwenhuijsen, L.; Luedde, M.; et al. U6 is unsuitable for normalization of serum miRNA levels in patients with sepsis or liver fibrosis. Exp. Mol. Med. 2013, 45, e42, doi:10.1038/emm.2013.81.

21. Rice, J.; Roberts, H.; Rai, S.N.; Galandiuk, S. Housekeeping genes for studies of plasma microRNA: A need for more precise standardization. Surgery 2015, 158, 1345-1351.

22. miRbase. Available online: http://www.mirbase.org/ (accessed on 24 September 2015).

23. Pfaffl, M.W.; Horgan, G.W.; Dempfle, L. Relative expression software tool (RES ${ }^{\mathrm{T} \odot}$ ) forgroup-wise comparison and statistical analysis of relative expression results in real-time PCR. Nucleic Acids Res. 2002, 30, 9, doi:10.1093/nar/30.9.e36.

24. Pasquinelli, A.E. MicroRNAs and their targets: Recognition, regulation and an emerging reciprocal relationship. Nat. Genet. 2012, 13, 271-282.

Sample Availability: Plasma samples are not available from the authors.

(C) 2015 by the authors; licensee MDPI, Basel, Switzerland. This article is an open access article distributed under the terms and conditions of the Creative Commons Attribution license (http://creativecommons.org/licenses/by/4.0/). 